\title{
Foundations of JSP Design Patterns
}

ANDREW PATZER

EDITED BY MATTHEW MOODIE 


\section{Foundations of JSP Design Patterns}

\section{Copyright $\odot 2004$ by Andrew Patzer, Matthew Moodie}

Originally published by Springer-Verlag New York, Inc. in 2004

All rights reserved. No part of this work may be reproduced or transmitted in any form or by any means, electronic or mechanical, including photocopying, recording, or by any information storage or retrieval system, without the prior written permission of the copyright owner and the publisher.

ISBN 978-1-59059-411-7 ISBN 978-1-4302-0736-8 (eBook)

DOI 10.1007/978-1-4302-0736-8

Trademarked names may appear in this book. Rather than use a trademark symbol with every occurrence of a trademarked name, we use the names only in an editorial fashion and to the benefit of the trademark owner, with no intention of infringement of the trademark.

Lead Editor: Steve Anglin

Technical Reviewer: James L. Weaver

Editorial Board: Steve Anglin, Dan Appleman, Ewan Buckingham, Gary Cornell, Tony Davis, Jason Gilmore, Chris Mills, Dominic Shakeshaft, Jim Sumser

Project Manager: Kylie Johnston

Copy Edit Manager: Nicole LeClerc

Copy Editor: Kim Wimpsett

Production Manager: Kari Brooks

Production Editor: Janet Vail

Compositor: Linda Weidemann, Wolf Creek Press

Proofreader: Greg Teague

Indexer: Brenda Miller

Artist: Kinetic Publishing Services, LLC

Cover Designer: Kurt Krames

Manufacturing Manager: Tom Debolski

The information in this book is distributed on an "as is" basis, without warranty. Although every precaution has been taken in the preparation of this work, neither the author(s) nor Apress shall have any liability to any person or entity with respect to any loss or damage caused or alleged to be caused directly or indirectly by the information contained in this work.

The source code for this book is available to readers at http://www. apress.com in the Downloads section. 


\section{Contents at a Glance}

About the Author $\ldots \ldots \ldots \ldots \ldots \ldots \ldots \ldots \ldots \ldots \ldots \ldots \ldots \ldots \ldots \ldots \ldots \ldots \ldots \ldots \ldots \ldots \ldots \ldots$

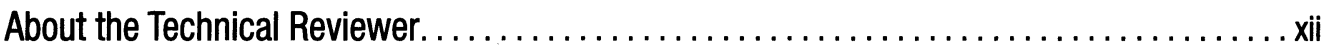

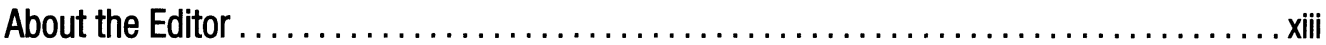

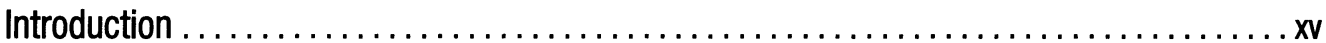

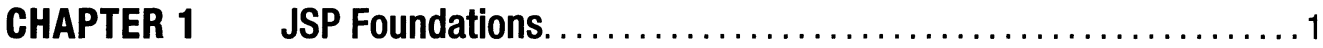

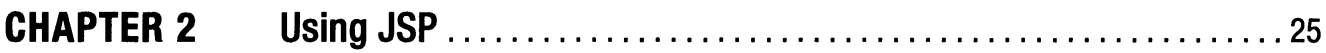

CHAPTER 3 Role Separation with JavaBeans $\ldots \ldots \ldots \ldots \ldots \ldots \ldots \ldots \ldots$

CHAPTER 4 Role Separation with Custom Tags ..................... 75

CHAPTER 5 Development Using Patterns ....................... 103

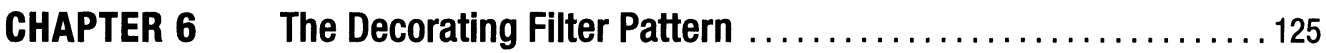

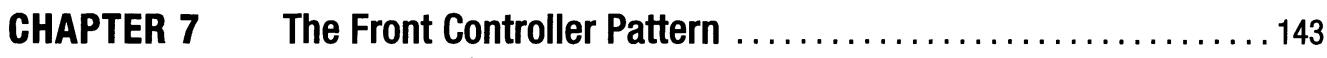

CHAPTER 8 The View Helper Pattern ........................... 167

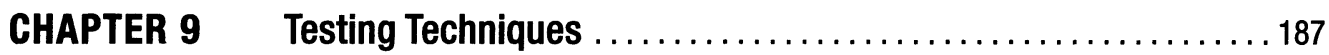

CHAPTER 10 Deployment Techniques.......................... 199

CHAPTER 11 Application Frameworks ........................... 215

CHAPTER 12 Putting It All Together.............................

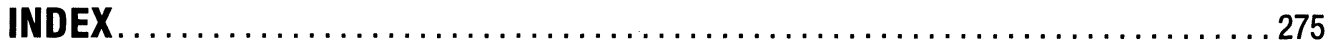




\section{Contents}

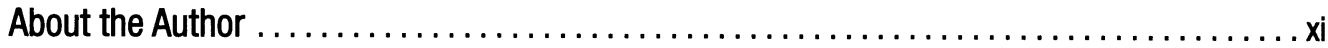

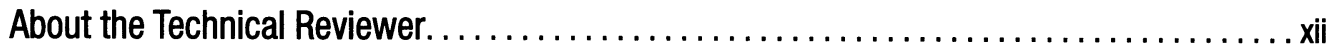

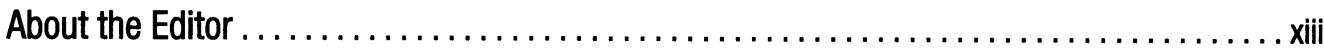

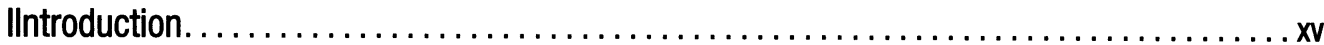

\section{CHAPTER 1}

JSP Foundations $\ldots \ldots \ldots \ldots \ldots \ldots \ldots \ldots \ldots \ldots \ldots \ldots \ldots \ldots \ldots \ldots$

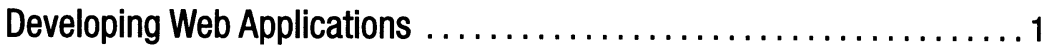

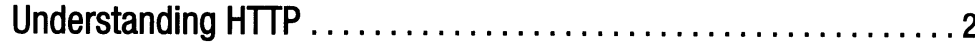

Understanding the Components of a Web Application. ........... 3

Developing J2EE Web Applications $\ldots \ldots \ldots \ldots \ldots \ldots \ldots \ldots \ldots, \ldots$

Understanding Web Containers .......................

Understanding EJB Containers ........................6 6

Understanding the Structure of a J2EE Application ...........6 6

Introducing Patterns for Web Application Development . . . . . . . . . . 6

Introducing the Servlet Model . . . . . . . . . . . . . . . . . . . . . . 7

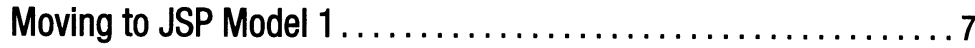

Moving to JSP Model $2 \ldots \ldots \ldots \ldots \ldots \ldots \ldots \ldots \ldots \ldots \ldots$

Introducing Enterprise Patterns . . . . . . . . . . . . . . . . . . . 9

Learning JSP Basics . .................................. 9

Processing JSP Pages.............................. 9

Understanding the Structure of a JSP Page . ............... 11

Introducing the Expression Language $\ldots \ldots \ldots \ldots \ldots \ldots \ldots 13$

Using the JSTL.................................... 14

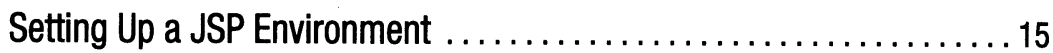

Choosing a Development Environment .................. 15

Picking an Application Server . . . . . . . . . . . . . . . . . . . . . . 15

Selecting a Database ............................... 16

Building a Simple JSP Application . . . . . . . . . . . . . . . . . 18

Designing the Page .............................. 19

Establishing a Database Connection ................... 20

Generating Rows of Customers ...................... 20

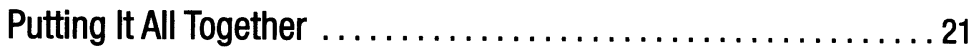

Summary $\ldots \ldots \ldots \ldots \ldots \ldots \ldots \ldots \ldots \ldots \ldots \ldots \ldots \ldots \ldots, 22$ 


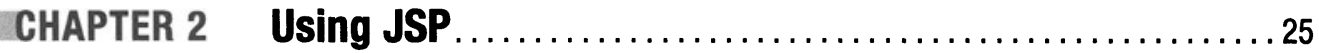

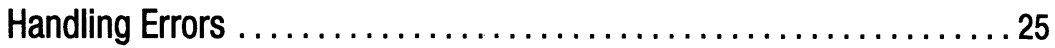

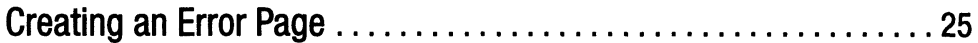

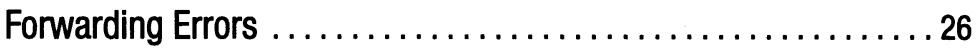

Including Other Files ................................ 28

Including Files at Compile Time....................... 30

Including Files at Runtime $\ldots \ldots \ldots \ldots \ldots \ldots \ldots \ldots \ldots, \ldots \ldots \ldots$

Processing Form Data .............................. 33

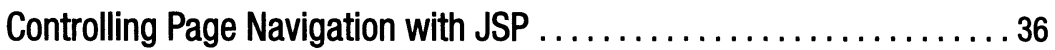

Maintaining State ................................... 38

Initializing and Cleaning Up JSP Pages $\ldots \ldots \ldots \ldots \ldots \ldots \ldots \ldots \ldots 41$

The Superclass. ................................. 42

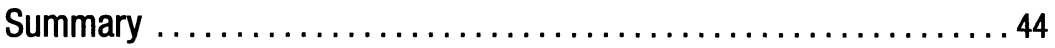

CHAPTER 3 Role Separation with JavaBeans $\ldots \ldots \ldots \ldots \ldots \ldots \ldots 45$

Introducing JavaBeans $\ldots \ldots \ldots \ldots \ldots \ldots \ldots \ldots \ldots \ldots \ldots, \ldots \ldots \ldots$

Building a JavaBean ............................. 46

Using a JavaBean in a JSP Page. ...................... 47

Accessing Bean Properties.......................... 47

Dealing with Large Sets of Data......................... 49

Creating the Solution. ................................. 50

Showing an Example............................. 57

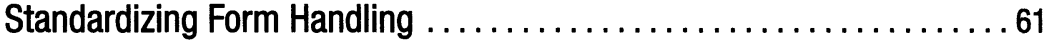

Creating the Solution. ............................. 61

Implementing a Form-Handling Solution $\ldots \ldots \ldots \ldots \ldots \ldots \ldots 62$

Using the Form-Handling Solution $\ldots \ldots \ldots \ldots \ldots \ldots \ldots \ldots 72$

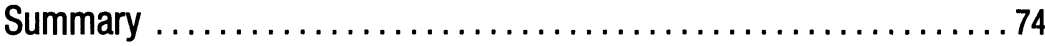

CHAPTER 4 Role Separation with Custom Tags ................... 75

Using Custom Tags . ................................. 75

Looking at a Simple Tag Example......................... 78

Implementing the Tag Handler Class . . . . . . . . . . . . . . . 78

Creating the Tag Library Descriptor . . . . . . . . . . . . . . . . . 80

Declaring the Tag Library ........................... 81

Using Your Tag Library in a JSP Page . . . . . . . . . . . . . . 81

Processing Body Content. . . . . . . . . . . . . . . . . . . . . . 82

Seeing a Body Tag in Action. . . . . . . . . . . . . . . . . . . . 83

Nesting Tags $. \ldots \ldots \ldots \ldots \ldots \ldots \ldots \ldots \ldots \ldots \ldots \ldots \ldots \ldots, \ldots \ldots \ldots$ 
Refining the Product List Page $\ldots \ldots \ldots \ldots \ldots \ldots \ldots \ldots \ldots \ldots . \ldots 93$

Creating the Product Display Tags ....................... 94

Using the Tags on the Page ........................... 97

Introducing Simple Tags ............................. 100

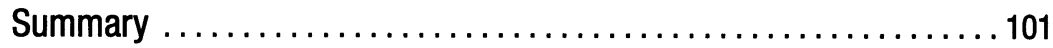

CHAPTER 5 Development Using Patterns ........................ 103

Why Use Patterns? ................................ 103

They're Proven Techniques ......................... 104

They're Reusable................................. 104

It's a Common Vocabulary ......................... 104

Introducing the J2EE Patterns Catalog . ..................... 104

Looking at Presentation Design Patterns ...................... 105

Understanding MVC ................................ 106

Seeing MVC in Action .................................. 108

Setting Up the Application ......................... 109

Defining the Model. .................................111

Setting the View................................ 114

Building the Controller.......................... 120

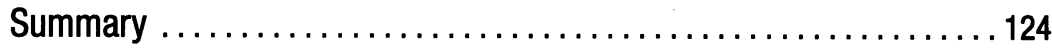

CHAPTER 6 The Decorating Filter Pattern $\ldots \ldots \ldots \ldots \ldots \ldots \ldots \ldots \ldots \ldots \ldots \ldots \ldots \ldots$

Defining the Pattern ................................. 126

Applying Strategies................................ 126

Developing a Custom Filter Strategy .................. 126

Using a Standard Filter Strategy ...................... 127

Applying the Decorator Filter Pattern..................... 128

Creating the Filter Class .......................... 128

Declaring the Filter............................... 130

Mapping the Filter to a URL ....................... 130

Using Filters to Log HTTP Requests ................... 130

Using Filters to Log HTTP Responses.................. 135

Summary ....................................... 141

CHAPTER 7 The Front Controller Pattern. ...................... 143

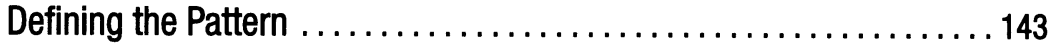

Developing Strategies............................... 144

JSP Front vs. Servlet Front Strategy . ................. 145 
Request Helper Strategy .......................... 146

Command and Controller Strategy ................... 147

Resource Mapping Strategies ........................ 148

Applying the Front Controller Pattern...................... 149

Revisiting MVC: An Example........................ 149

Using Filters with a Front Controller ................... 165

Summary ...................................... 165

CHAPTER 8 The View Helper Pattern ......................... 167

Defining the Pattern ............................... 167

Implementing View Helper Pattern Strategies ................. 168

Implementing the JavaBean Helper Strategy ............... 168

Implementing the Custom Tag Helper Strategy .............. 169

Implementing the Model Separation Strategy .............. 170

Applying the View Helper Pattern ........................ 171

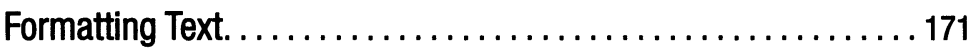

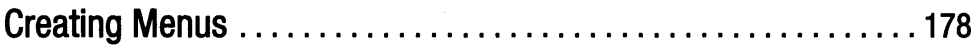

Creating Custom List Formats ..................... 182

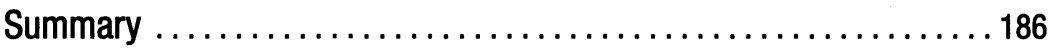

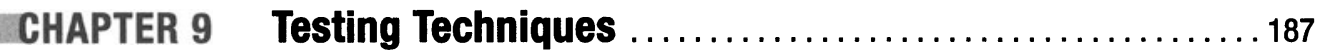

Why Is Testing So Important? ......................... 187

Understanding Regression Testing .................... 188

Breaking Regression Testing into Units . . . . . . . . . . . . 188

Building a Unit Testing Framework. ...................... 189

Using JUnit ................................ 189

Adding Unit Tests to Your Application Framework .......... 192

Testing for Performance . .................................. 194

Using JMeter. . . . . . . . . . . . . . . . . . . . . . . . . 195

Viewing the Results............................ 197

Summary ..................................... 197

CHAPTER 10 Deployment Techniques .......................... 199

Managing the Development Process $\ldots \ldots \ldots \ldots \ldots \ldots \ldots \ldots \ldots 200$

Source Control $\ldots \ldots \ldots \ldots \ldots \ldots \ldots \ldots \ldots \ldots \ldots \ldots \ldots, \ldots \ldots \ldots 1$

Code Reviews...............................201

Automated Build Procedure ....................... 202

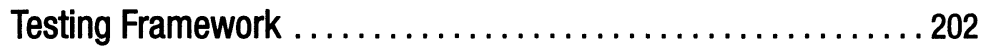

Change Management ............................ 203 
Automating the Build Process with Ant $\ldots \ldots \ldots \ldots \ldots \ldots \ldots \ldots 203$

Creating a Simple Build Script. ...................... 203

Integrating with Source Control...................... 206

Building WAR Files ............................. 208

Precompiling JSP Pages........................... 209

Accounting for Different Platforms .................... 211

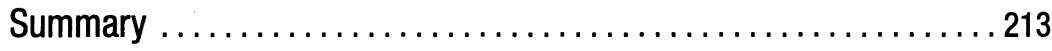

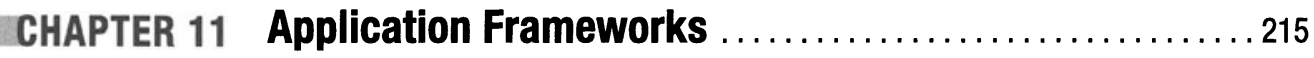

Designing a Framework ............................ 215

Building a Web Application Framework $\ldots \ldots \ldots \ldots \ldots \ldots \ldots \ldots \ldots \ldots \ldots$

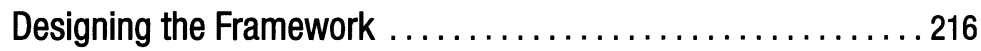

Documenting the Framework ...................... 217

Logging Error and Debug Messages $\ldots \ldots \ldots \ldots \ldots \ldots \ldots \ldots 218$

Building a Database Helper . . . . . . . . . . . . . . . . . . . 220

Authenticating Users ............................. 224

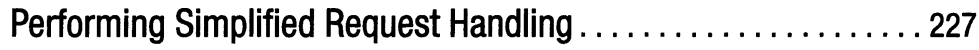

Introducing Common UI Components.................. 233

Deploying a Framework ............................ 237

Creating the Framework's Build Script. . . . . . . . . . . . . . 237

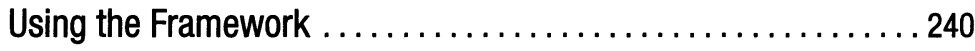

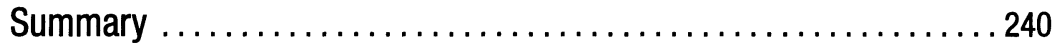

CHAPTER 12 Putting It All Together $\ldots \ldots \ldots \ldots \ldots \ldots \ldots \ldots \ldots \ldots \ldots \ldots \ldots \ldots \ldots \ldots \ldots \ldots$

Building an Online Catalog. .......................... 241

Designing the Application........................... 241

Setting Up the Application . . . . . . . . . . . . . . . . . . . . 242

Logging Into the Application ........................... 250

Viewing the Catalog .............................. 252

Accessing the Shopping Cart ......................... 265

Building the Catalog Application........................ 273

Summary ....................................... 274

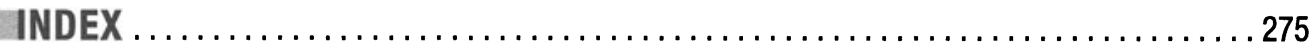




\section{About the Author}

ANDREW PATZER is a technical architect for BORN Information Services. He has authored several Java titles, including the best-selling Professional Java Server Programming (Wrox Press, 1999), which was the first book to cover J2EE technologies. Andrew continues to learn new technologies and educate others on their practical applications within the enterprise IT landscape through both speaking and writing. 


\section{About the Technical Reviewer}

IJAMES (JIM) L. WEAVER has served as a systems architect and developer for more than 25 years, specializing in leading-edge software development. He has designed and developed numerous business, manufacturing, engineering, and educational applications. He has authored books on the Java programming language, including Beginning J2EE 1.4: From Novice to Professional (Apress, 2004) and Inside Java (New Riders, 1997). Jim is recognized for his understanding of online learning standards and systems, his unique ability to imagine solutions to complex technical problems, and his relentless pursuit of technical quality. 


\section{About the Editor}

MATTHEW MOODIE enjoys a life of fun in Glasgow, Scotland. He's a keen novice gardener with a houseful of plants. He'd like to thank Laura for her love and friendship. 
his book is for developers of all levels that want to make their projects efficient, flexible, and well designed. In other words, this book is for every developer who works with JSP and servlets.

The book begins with a quick introduction to JSP for those who are new to JSP, those who may be a bit rusty following the release of a new specification, or those with a lack of recent experience. Therefore, Chapters 1 and 2 cover the basics of the JSP 2.0 Specification and describe the syntax and commands used to produce dynamic content. The best practice theme of the book is introduced here so that you don't pick up bad habits from the beginning. It's this reliance on best practices that means you don't need to know much, if any, Java to use this book; the JSP 2.0 Specification makes it easy to avoid Java altogether and still achieve excellent results.

After the two introductory chapters, you'll move into the real thrust of the book. Chapters 3 and 4 take the roles of Java developer and page designer and separate them firmly but fairly. This ensures that each side of a web application is clearly defined and enforces areas of responsibility. In other words, a page designer doesn't get to work with the innards of the application, mainly because the JSP 2.0 Specification makes it easy for a developer to create designer-friendly interface, and the developer works with the application's data model. Again, Java used to be at the heart of this separation, but now little Java is needed to be an effective JSP developer.

Once the distinction between developer and designer has been set up, the natural progression is to show you how to present the designer-friendly interface to a designer. This is accomplished by separating the application into layers, or tiers as they are commonly known, and by creating a web tier (called the view), a middle tier containing control logic (part of which is the controller), and a data layer (the model). The view is the part of the application that the designer will work on, and it's here that design patterns can play an important part in simplifying and streamlining the public face of the application.

Chapters 5, 6, 7, and 8 present design patterns that have been tried and tested over many years of web development. They're standard and widely used in the industry and are therefore well understood. Each design pattern solves a certain problem associated with the view of the application. Chapter 5 lays the foundations for these design patterns by describing the ModelView-Controller (MVC) architecture already mentioned. (You may hear it called Model 2 architecture.) All the design patterns require you to have an MVC architecture.

Chapter 6 introduces the Decorating Filter pattern, which you can use to intercept HTTP requests and responses and do what you like with them. This is one topic that requires you to know Java because it's the Java Servlet Specification that defines filters and not the JSP Specification. Filters can log activity in your application, redirect requests based on IP addresses, and much more.

Chapter 7 is the core of the pattern methodology section. It describes the Front Controller pattern, which uses a single component to control all entry to the application. In other words, it receives all the requests, processes them (sometimes with the help of additional components), 
and decides which part of the view (that is, which web page) the user should see as a result. The controller is where all the logic of the application is stored, allowing you to centralize all your application code. This centralized, single point of entry allows you to add more functionality easily. Chapter 8 finishes the pattern section with a look at the View Helper pattern, which is the main technique for adding application-specific functionality to the view. This is the fabled designer-friendly interface made corporeal.

This marks the end of the main coding/best practice material and is the beginning of the methodology and deployment chapters. Chapter 9 shows you how to test your application once you've written it. This is a crucial step, and no serious piece of code should go into production without passing a serious of tests. Luckily, this chapter makes it easy for you to set up your own test suite using the JUnit test framework, which is open-source, of course. Once you've tested that your application works as expected, you should ideally load test it. This ensures you get the best performance possible from your application. However, this is sometimes possible only once the application has gone into production.

Chapter 10 shows you how to organize your code and how to automate the deployment process. These subjects are closely related, as automated deployment requires organized code. If your project is large, you may have more than one developer working on it, so organization is even more important. Automating deployment makes life easier for all concerned by taking away the chore of deployment, even for the smallest change to source code. This chapter discusses general programming theory first and then shows how to use JSP and servlets in practice.

Chapters 11 and 12 pull the rest of the book together by describing an application framework that embodies all the ideas and theories of the previous ten chapters. This application serves as a reference implementation for any application framework you may want to implement or use in the future. 